\title{
TRANSMISSION AND DISTRIBUTION INDUSTRY PROJECT MANAGEMENT INFORMATIONIZATION
}

\author{
Yingying Yu \\ School of Management, Shanghai University, Shanghai 20044; \\ Chongming Zhu \\ Xiamen RuHong technology co., LTD, Xiamen 361000
}

\begin{abstract}
Nowadays, there are thousands of transmission and distribution equipment production enterprise in the scale of electric power industry. Their products' homogeneity is serious. As China's economy is slowing, competition between enterprises has become increasingly fierce, the price of the products is cheaper, enterprises urgently need to seek breakthrough of management. Transmission and distribution equipment production enterprise has an obvious feature that the product is according to project operation, so the implementation of lean project management is the key to the enterprise to reduce the cost, improve efficiency and expand sales.
\end{abstract}

Keywords: project management; informationization; reduce the cost; improve efficiency

JEL code: L6

\section{Introduction}

Nowadays, according to the continuous development of the Internet of things, service network, industrial robots, and the digital and intelligent technology, the innovation of the industry 4.0 is promoted in a certain way. This is a huge shock for manufacturing ( $\mathrm{Li} \mathrm{Ke}, 2016)$. A large number of studies have shown that, the popularization and application of information and communication technology have two sides. On the one hand, represented by German industrial 4.0, it can reduce transaction cost of information search, make communication be more smoothly, so as to improve the efficiency of industrial production and promote enterprise organization change; On the other hand, information and communication technology combining with other technologies and other industries, can also improve enterprise efficiency directly or indirectly (Zhang Lidong, 2016). As one of the traditional manufacturing industries, transmission and distribution, in order to enhance their competitiveness, need pay more attention to the management informatization. The lean management thought as an important achievement in the enterprise management area, is an important strategic to guide the enterprise authors efficiency, expand sales (James Womack, Dan Jones, 2001). 


\section{Industry Background}

China is a great manufacturing power. China's manufacturing output in 2010 reach to $19.8 \%$ of the world. China becomes the second largest industrial country, behind America, and a veritable "world factory" (Zhang Haijian, 2016). Nowadays, China's manufacturing industry still relies on a large number of human. Although, machinery has been widely used, mechanization level is not high, and productive forces still can't be replaced by machinery completely. Different from some developed countries, our country is limited by the development and the history of the industry. A lot of mechanical and repeating work is still performed by the human. The participation rate of information technology in the process of producing is insufficient, even in many factories computer technology is still not applied widely. Information delivery and collection work still relies on the way of backward, which wastes a great deal of manpower and material resources to complete. Therefore, the enterprise seeks for the breakthrough in management level. A successful implementation of the lean management system, is an inevitable choice for enterprises. Only through lean management strategy to achieve the transformation and upgrading of the enterprise, can the enterprise achieve a greater competitive advantage in the industry (George Michael L, 2003; Eliyahu M Goldratt, 1990).

\subsection{Industry Research}

We have done research on large foreign enterprises (Xiamen Schneider Electric Co., Ltd., Xiamen ABB high / medium / low voltage switchgear Co., Ltd.), state-owned enterprises (Xu Ji electric co., LTD., Fuzhou Tian Yu electric co., LTD), private enterprises (Guangdong Jin Huilong switch co., LTD., Shenzhen double surplus electric co., LTD., etc.) in the transmission and distribution industry. In case of Guangdong Jin Huilong switch co., LTD., the products number for KYN28-12 and KYN61-40.5 account for 70\% of the company sales. The cycle of the project management of the whole process (From participating in bidding to the bid, the technical agreement signed, business contract, engineering design, procurement, production, inventory, transportation, installation, debugging, acceptance, sending until quality retention money collection) need more than one year, from the business contract to factory delivery takes 45 days on average (Wang Jian, 2014). A lot of interference will happen in the process of project operation (such as the delivery date change, design change, shortage of materials, quality abnormal, equipment failure, etc.). Under the conditions of the complex operation, $80 \%$ of the enterprises have following problems, for example, the project on-time delivery rate is low, the design changes frequently, serious material shortage, the fraction defective of parts and the number of manufacturing defects both are high. In order to meet customers' requirements, the way enterprises usually adopt is to work overtime, add manpower, add site, add processing equipment, outsourcing processing and so on (Wu Zhihui, 2016; Zhang Haijian, 2016). Although there are ERP systems to help enterprises to standardize the process, the above problems the enterprise have can't be solved. Guangdong Jin Huilong switch co., LTD achieved the project delivery time shortened by $30 \%$, productivity increased by $40 \%$, a $50 \%$ drop in inventory turnover days in 2016 by means of the implementation of lean project management informationization and improvement of the 
production site. This article mainly shows the informationization of project management in the whole process how to help Jin Huilong to achieve this change in more than one year $(\mathrm{Xu}$ Guanglin, 2014).

\subsection{The Situation Before Informationization}

According to investigation, the study found that Jin Huilong without using lean management system, main problems existing in the whole process project management can be summed up in the following aspects:

\subsubsection{Delivery Time is Difficult to Secure}

Normally, orders are reviewed by OA system, engineering design department review the BOM and drawings issued date first, and then the purchasing department review purchase part of the date of delivery, finally planning department review project delivery date. Due to the completion date of each node is not reversed according to the customer request delivery, design, procurement, production capacity and the influence of the order in hand do not take into account as well, the delivery time can't meet the requirement of the customer, or the delivery time promised to the customer will be delay.

\subsubsection{Project Schedule is not Reasonable}

Planning department usually tracks overall progress of the project by EXCEL tables, each department tracks the project schedule in the department by EXCEL tables too. Between departments deliver project messages by telephone, mail, print documents, OA system and so on. The plan yield rate is low because each department's plan is unreasonable. For example, BOM and drawings issued by the department of engineering are not urgently needed by purchasing department and production department. Instead, what urgently needed by purchasing department and production department are not issued. For another instance, the arrival of the procurement of materials are not urgently needed by production, however, what the production department urgently needed are not delivered on time.

\subsubsection{Processing and Feedback of the Problems in the Project are not in time}

Each department records problems by using EXCEL tables or notebooks. However, no one knows exactly how many problems of the project exist in the whole operation process, how many are being processed and how many are needed to be handled with, how is the processing progress now, which problem will affect the production and delivery of the goods, and if there is a root cause analysis, corrective and preventive to the key problem. Although each department is busy fighting fires, and the information about the same question is passed back and forth between each department each management level of, a lot of time is wasted on communication, it is still hard to see the whole picture of the project schedule, and the delivery time is always delay. 


\subsubsection{Lacking of Effective Quality Control Measures}

Production process control is lax in each process, the management is not standard, the quality control measures are effective enough, these all lead to the appearance of the products problems in customer site, and the problems are not prevented effectively.

\subsection{The Improvements after Informationization}

By using the project management system, in the field of project management in the company Jin Huilong has got the following improvement:

\subsubsection{Processed Management of Project, Update the Data in Time}

Carding and optimization of the project management process, through the system to realize the whole process management, all reports and other related data in each department can be updated automatically. Departments can get the information you need in different stages timely and accurately.

\subsubsection{Improve Work Efficiency, Data Accuracy and Timeliness}

As for the documents and information transmission between different departments, by using information flow process such as online tracking, online submission, examination and approval, online sharing, automatic information reminding and so on, the repetitive work between different departments has been reduced, the timeliness and accuracy of the data update have been improved as well.

\subsubsection{Implement the Synchronization Between System and Actual, Promote Operational Efficiency}

Both the level 1 plan (total project plan) and level 2 (each phase plan) plan of the project are settled through the system, and planning departments make the plan of project level, each department control level 2 plan, planned tasks are implemented to project director of each department. By expanding each department internal briefings to promote secondary plan, expanding the interagency briefings promoting primary plan, make sure the system and the actual synchronization, realize the efficient operation of the project.

\subsubsection{Improve Data Sharing}

By sweeping the whole process of production process, recording the production schedule, inspection schedule and the defects of progress, realize the whole process of production data collection, so that each department can see the real-time production situation of each project. 


\subsubsection{Promote the Visual Management of Problem Solving}

This system realized the visual management of problem solving. Online problem management whose design refers to $8 \mathrm{D}$ model, allows each employee to report all kinds of problems according to their findings to the system. Those responsible are ordered to fill out the online problem processing state or upgrade the problem according to the problem upgrade process; Company managers can supervise processing state of all the problems within their own control limitation, and promote the solution of the problem quickly through the morning session system.

\subsubsection{KPI Monitoring}

The whole process of project management data acquisition, makes the KPI be monitored automatically. KPIs are divided into four categories: the on-time rate of each node t, output of each node, the working efficiency of each node, the execution cycles of each node. According to the daily inspection, company managers can know which nodes are out of the question. And the online submission and the problem solving can make continuous improvement.

\section{3 . Example of Jin Huilong Project Management System}

\subsection{Enterprise management informatization and project management informatization}

Before Jin Huilong company carried out the project management informationization, they have launched the Ufida U8 ERP system which is highly localized in China. This ERP system makes the management capacity of Jin Huiling company to achieve the middle level of the industry. And it mainly reflects on the very good application in the clear accounts of the warehouse-in and sales, inventory accuracy, MRP (material requirements planning) and ROP (reorder point plan). In this way, the project delivery time, per capita output, as well as the profit margin have achieved the average level of the industry. Also, the inventory has been controlled in a benign interval. However, the function in the field of operations management of Yongyou U8 system is relatively weak. It is the industry general system, not based on customization system in transmission and distribution industry. And it cannot make a synchronous optimization based on the enterprise management to promote too (Wang Jian, 2014). For example, the system can't know the operation progress of each project and the exceptions produced during the process; The state of the production and inspection of each product can't be known by this system; The exceptions occur during the execution of the project can't be feedback, tracked or deal with. Therefore, in order to improve the performance of operating further, Jin Huilong company puts forward to the implementation of the project management informatization. Based on the original ERP system, combined with the advanced ideas of lean management, Jin Huilong company optimizes the management style, uses the additional part to strengthen the original ERP system. Following pictures are the enterprise information system flow chart before and after adding the project management model: 


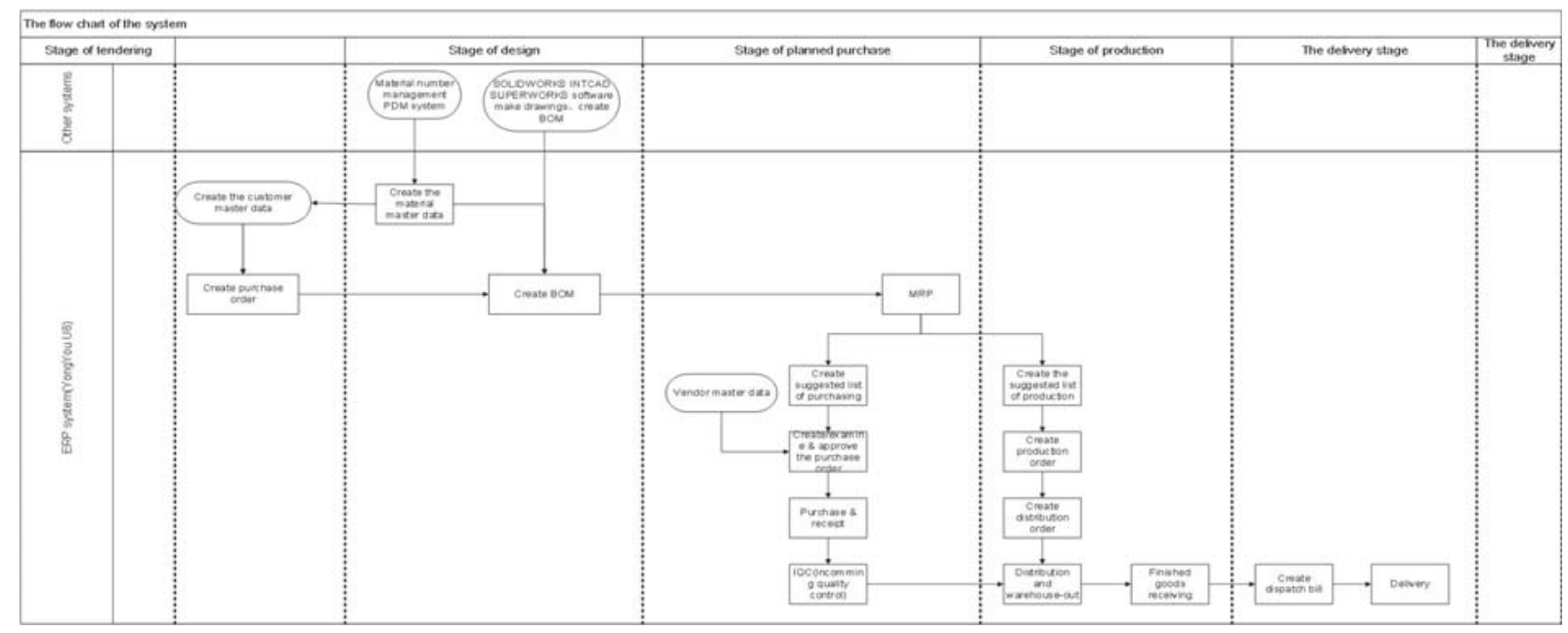

Figure 1. ERP system flow chart before adding the project management model

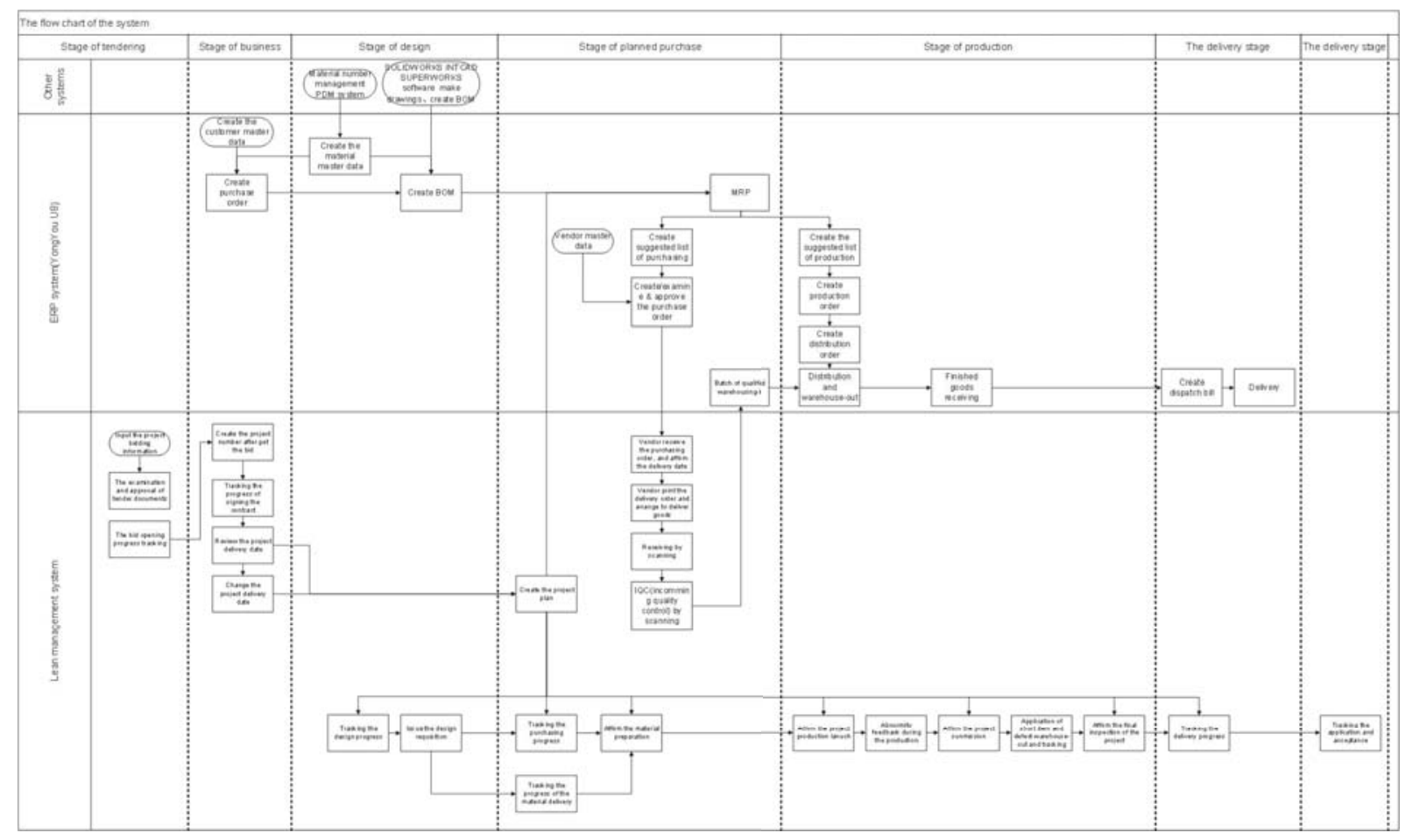

Figure 2. ERP system flow chart after adding the project management model

According to the above two flow charts which have obvious contrasts, it is clear that the project management based on the original ERP system, and combined with the advanced ideas of lean management, has strengthened the original Ufida U8 ERP system pertinently. Project management informatization makes the original Ufida U8 ERP system to be much stronger and more comprehensive. The whole idea is ERP system + project management informatization. On the one hand, it still use Ufida U8 ERP system to manage several modules such as warehouse-in, sales, inventory, MRP and so on. On the other hand, considering about the operations management, the project management informatization plays a great role on it. ERP system and Lean management system focus on different modules of the enterprise management, however they cooperate with each other perfectly. In this way, the 
model of enterprise management gets optimized, the costs of management reduce, and the profits of enterprise increase.

\subsection{Current situation of project management informatization}

Based on the principle of designing an enterprise information management information system, and considering about the current informatization level of Jin Huilong company, lean management system pay attention to design and develop a both practical and efficient project management informatization module, which is an optimized ERP system with high usability. The following content would like to show the three main parts of the project management informationization to display the implementation of project management information system.

\subsubsection{Project Execution Status}

Case 1: This page shows the project execution status of each milestone. The initialization interface displays all the project execution status in the company. Besides, according to the search conditions, you can get target project execution status or expired unfinished projects and plans for the future much more quickly by pressing the button. Meanwhile, choose one project number, more project information will be displayed.

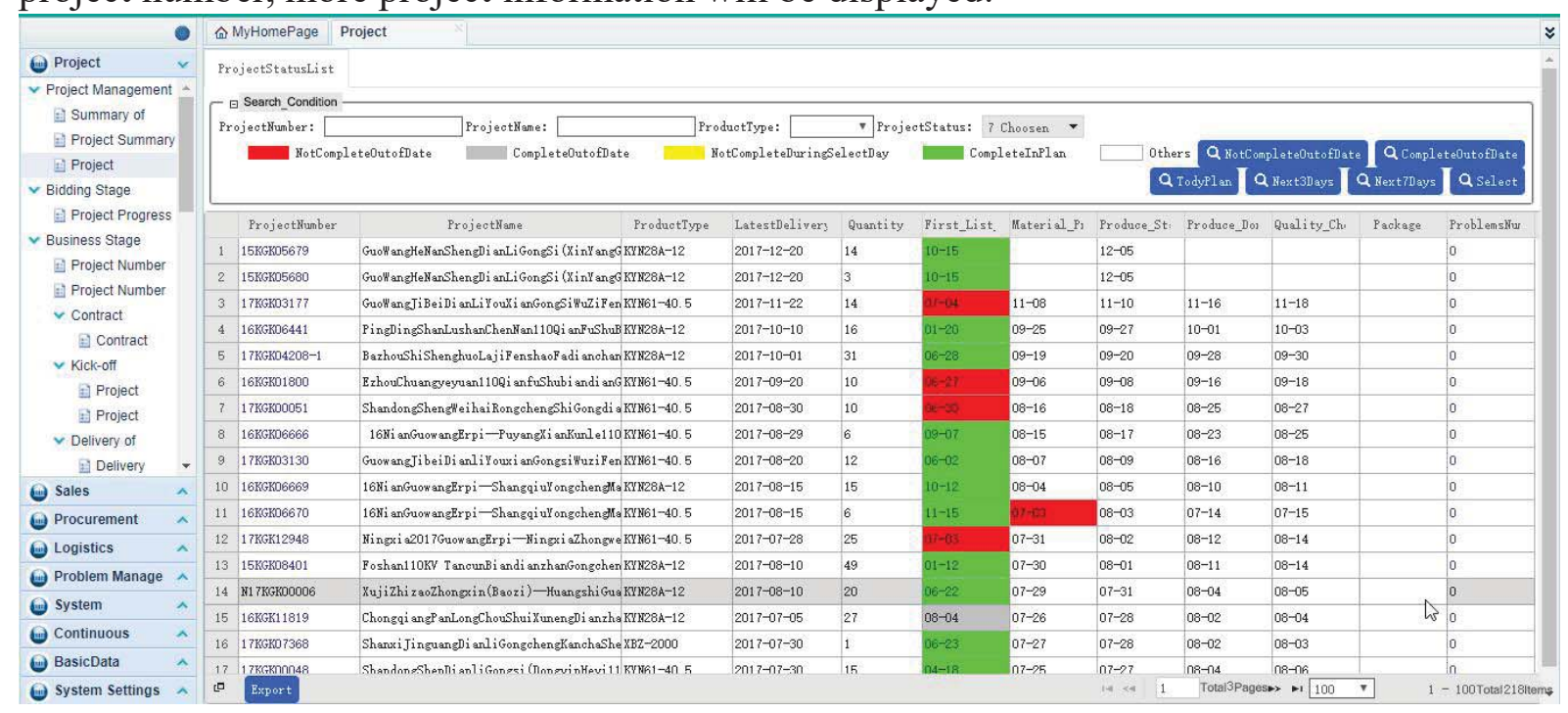

Figure 3. project execution state display figure

Use different colors to distinguish each milestone execution progress of a project: the green means have been finished on time, the red refers to unfinished on time, the yellow means which is unfinished in the query period, the gray refers to have been ended over the planning time. As a result, the project managers can control the execution state of each milestone directly and conveniently, and each phase of the corresponding condition can be grasped timely. At the same time, it is advantageous for the project managers to find out problems and put forward the corresponding solutions quickly. 


\subsubsection{Project Design Progress}

Case 2: This page is used to show the project execution status of design. The initialization interface displays the whole design stages of the project. Besides, according to the search conditions, you can get target project design progress or expired unfinished projects and plans for the future much more quickly by pressing the button. Meanwhile, choose one project number, more designing details will be displayed.

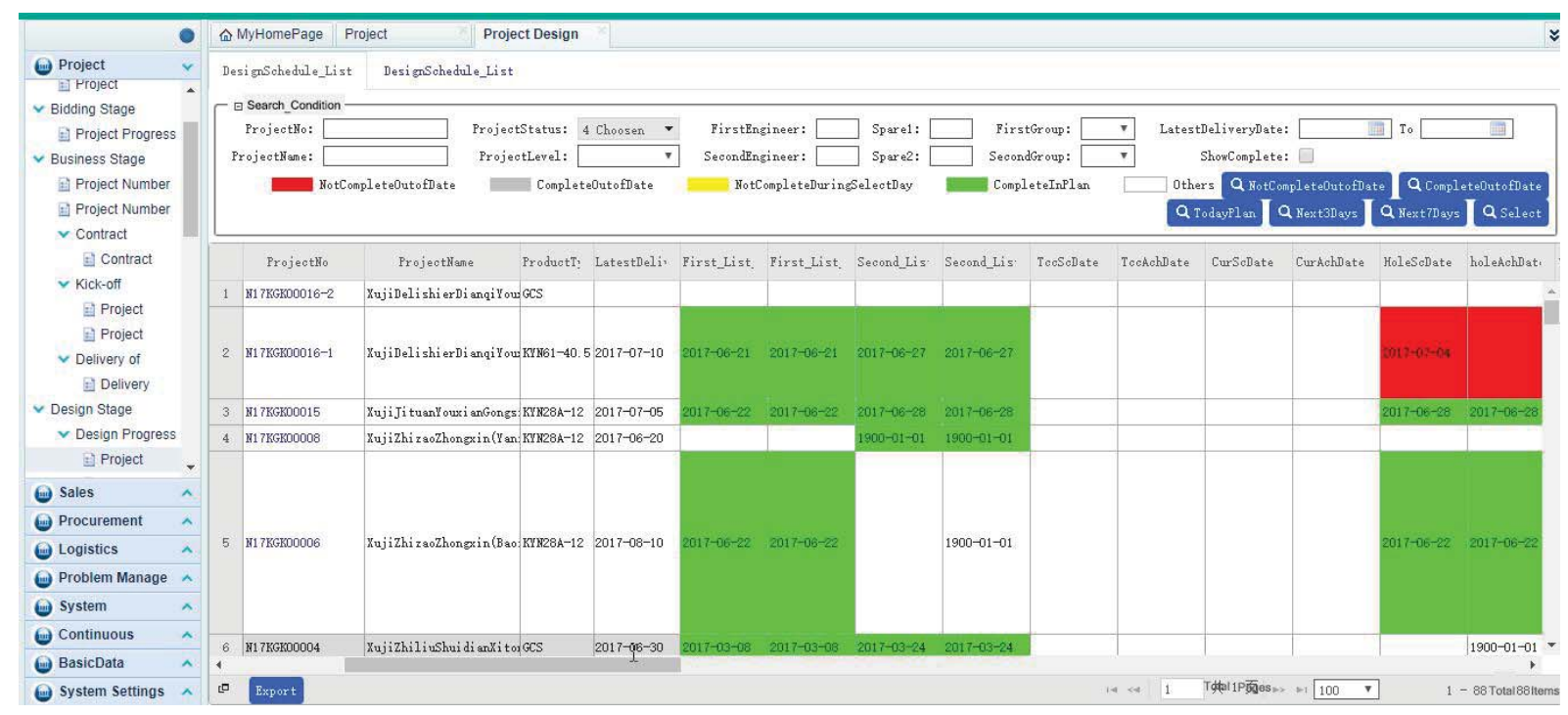

Figure 4. The project design progress display figure

Similar to the project execution status of each milestone, use different colors to distinguish each milestone execution progress of a project: the green means have been finished on time, the red refers to unfinished on time, the yellow means which is unfinished in the query period, the gray refers to have been ended over the planning time. It is convenient for the project leaders to master the schedule of project design progress timely, and to control the situation that the project is carried out.

\subsubsection{Problem Processing}

Case 3: This page shows all the processing progress of company's internal problems which are occurred during the execution of projects. And the progress is communicated in each department through the morning session system. Besides, according to the search conditions, you can get target processing progress of problems much more quickly by pressing the button. So that, you can know how the project is going on quickly. 


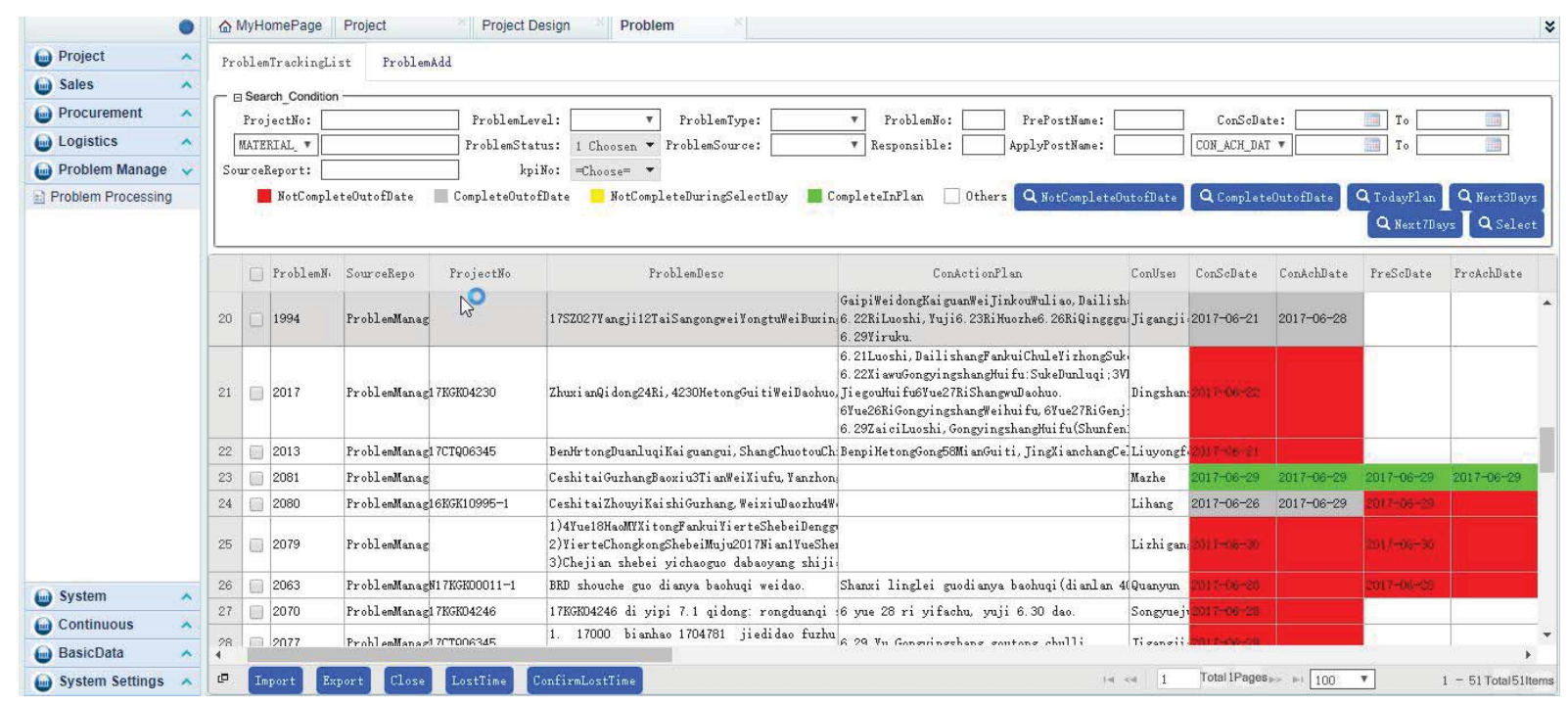

Figure 5. problems progress display figure

Similar to the above two modules, use different colors to distinguish each milestone execution progress of a project: the green means have been finished on time, the red refers to unfinished on time, the yellow means which is unfinished in the query period, the gray refers to have been ended over the planning time. It is easy for the project leaders to know the status of the problem that is dealt with, and to ensure the project is carried on smoothly as scheduled.

\subsection{Achievement of project management informatization}

Jin Huilong company that implements the project management informationization by using the lean management system, have been generated great revenues, mainly including the following areas: output value of the enterprise, project delivery date, inventory turnover period and so on. Following paragraph aims to display the achievement that Jin Huilong company make on project delivery date emphatically. Table 3-1shows the comparison of the project delivery time in each stage between 2015 and 2016, and the expectation of target delivery time in 2017.

Table 1. Comparison of delivery date table

\begin{tabular}{|l|l|l|l|l|l|l|l|}
\hline Jin Huilong & $\begin{array}{l}\text { Design } \\
(\text { Day })\end{array}$ & $\begin{array}{l}\text { Purchasing } \\
(\text { Day })\end{array}$ & $\begin{array}{l}\text { Material } \\
\text { Preparation } \\
(\text { Day })\end{array}$ & $\begin{array}{l}\text { Production } \\
(\text { Day })\end{array}$ & $\begin{array}{l}\text { Final } \\
\text { Inspection } \\
\text { (Day) }\end{array}$ & $\begin{array}{l}\text { Packing\& } \\
\text { Dispatch } \\
\text { (Day) }\end{array}$ & $\begin{array}{l}\text { Total } \\
\text { (Day) }\end{array}$ \\
\hline Before (2015) & 50 & 37 & 3 & 5 & 10 & 3 & 108 \\
\hline After (2016) & 20 & 22 & 2 & 4 & 8 & 2 & 58 \\
\hline Target (2017) & 17 & 15 & 2 & 3 & 6 & 2 & 45 \\
\hline
\end{tabular}




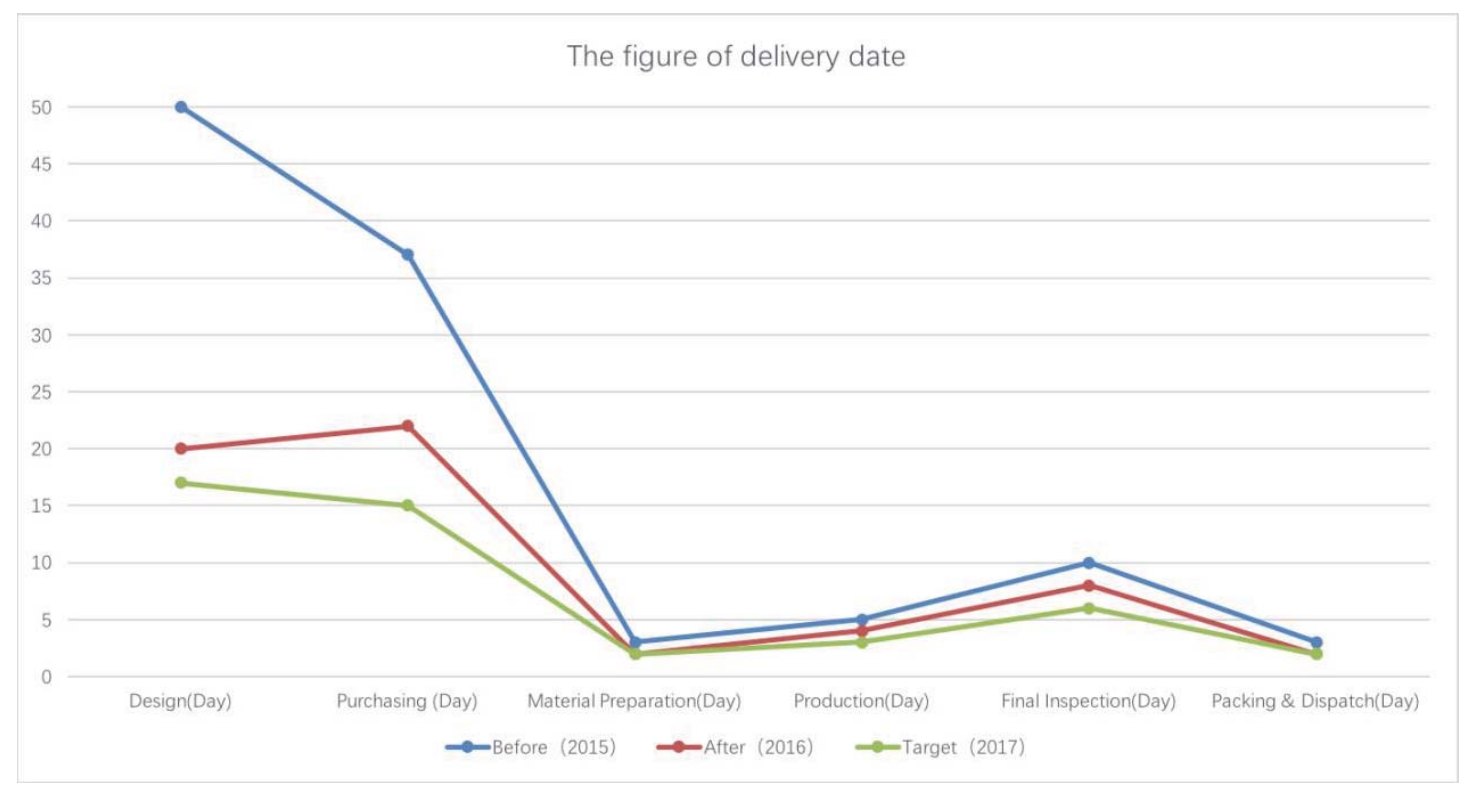

Figure 6. Comparison of delivery date

According to foregoing table and figure, it is obvious that not only the whole project delivery date, but also the delivery date of every stage, has a significant falling, through the project management informatization. Thus, the module of project management informatization in the lean management system has played a huge role on improvement of project management in enterprise, and the system will continue to give play to the significant value in the future.

\section{Conclusion}

From the above description of the management problems that Jin Huilong meets befor the online project management system was used and the strategies they changed after the system used, you can see that Jin Huilong realized the qualitative leap on the management level. Through the whole process implementation project management informationization, the tradition project management style became routing management, all data get updated in time; The work efficiency, data accuracy and timeliness get improved; Achieve the synchronization of system implementation and actual situation, promote the operational efficiency; Improve data sharing; Promote the problems dealing with visual management; Implement key performance indicators (KPI) monitoring. Thus, the original management problems that Jin Huilong has for example, the delivery is hard to be guaranteed; get great improvement, management mode is optimized as well. Jin Huilong of original delivery guaranteed; Project schedule is unreasonable; Project problems in processing and feedback in time; Lacking of effective quality control measures, and so on, get great improvement, management mode was optimized.

Under the wave of in industry4.0, under the guideline of Chinese-made 2025, enterprise management informatization is the inevitable trend of enterprise progress and sustainable development, especially in the traditional manufacturing industry like transmission and distribution industry. The thick of business success is to grasp the essence of lean 
management, realize project management informatization of transmission and distribution industry, promote the optimization of traditional manufacturing management mode, reduce the costs and improve the efficiency, and maximize the corporate interests. In addition, according to the analysis, it is found that the lean management system is suitable for not only the state-owned enterprises but also foreign enterprises, the more varieties the company product has, the harder the management difficulty the enterprises are facing with, the greater the lean management system can play a role.. Industry giants like Schneider, ABB, as well as the subsidiaries of national power grid has been in the implementation of project management system.

As the promotion of global industry4.0, and the deployment of Chinese-made 2025 strategic, every industry accelerated the pace of the combination of the industrialization and informatization. Transmission and distribution industry as a traditional industry, there is speeding up two levels of differentiation between enterprises. The wisdom manufacturing enterprises that focus on lean management will gradually weed the traditional manufacturing mode of enterprises out. One of the key steps to realize intelligent manufacturing for transmission and distribution enterprises is project management informationization. As the system functions are further expanded, and the combination between system and automation equipment is realized, intelligent manufacturing will not be a dream any longer.

\section{References}

Eliyahu M Goldratt. Theory of constraints[M]. America. North River Press, 1990.

George Michael L. What is lean six sigma[M]. America. Mcgraw-Hill, 2003.

James Womack, Dan Jones. Lean manufacturing[M]. British. CRC Press,2001

Li Ke, Zhu Xinyue. Chinese-made, The 2025 steps[J]. The enterprise management, 2016, (2): 6-12.

Wang Jian. Smart Factory----China's manufacturing sector in recent future[J]. Smart Factory, 2016, 5: 20-22.

Wang Jian. Smart Factory 1.0 is the transformation of the concept which is put forward based on China's manufacturing reality [J]. Science of the world,2014,6:14-18

Wang Wei, Meng Tao. Managing change and innovation of industrial 4.0 trend[J]. Enterprise Management, 2014, 36 (1): 1-7.

Wu Zhihui. New thinking and new pattern of industrial 4.0 transformation and upgrading in traditional manufacturing[J]. Furniture, 2014,36(1):1-7.

$\mathrm{Xu}$ Guanglin. German makes industrial 4.0 information interconnection combined with 
traditional industries[J]. The inverter world, 2014, (3): 32.

Zhang Lidong. The path research of manufacturing industry transformation and upgrading under the background of Chinese-made 2025 [J]. Jiangxi academy of social sciences, 2016, (4): 43-47.

Zhang Haijian. The study of how will the China's manufacturing industry adapt to the global informationization tide [J]. Small and medium-sized enterprise management and technology, 2016, (2):140-141. 